\title{
Restored vision in a young dog following corticosteroid treatment of presumptive hypophysitis
}

\author{
Nina Marie Rzechorzek ${ }^{1,2^{*}}$, Tiziana Liuti ${ }^{2}$, Catherine Stalin ${ }^{3}$ and Katia Marioni-Henry ${ }^{2}$
}

\begin{abstract}
Background: Hypophysitis is an umbrella term for a group of disorders involving inflammation of the pituitary gland. A rare occurrence in humans, hypophysitis can produce a range of clinical signs including (but not limited to) visual deficits and diabetes insipidus. Only five cases of canine hypophysitis exist in the literature, all presenting in mature dogs with no visual deficits and a grave outcome. This case report describes the clinical and advanced imaging features of blindness-inducing presumptive hypophysitis in a dog, which rapidly resolved with medical management.

Case presentation: A 1-year-and-seven-month-old neutered male Standard Poodle presented with subacute blindness, ataxia, and polyuria/polydipsia (PUPD). Magnetic resonance imaging (MRI) detected a contrast-enhancing pituitary mass with perilesional oedema compromising the optic chiasm. Suspecting neoplasia, anti-inflammatory corticosteroid was commenced prior to radiation therapy planning. Complete resolution of neurological and visual deficits occurred within 12 days of starting steroid treatment. Repeated advanced imaging indicated macroscopic resolution of the lesion. An extended thyroid panel with insulin-like growth factor-1 analysis supported a diagnosis of hypophysitis. Resolution of PUPD was achieved with tapering courses of prednisolone and desmopressin; the dog has since been clinically normal for 14 months and treatment-free for 11 months.

Conclusions: To the authors' knowledge, this is the first instance in which a canine pituitary mass has demonstrated long-term resolution with palliative medical treatment alone, alongside reversal of associated blindness and presumptive diabetes insipidus. We suspect this lesion to be a form of hypophysitis, which should be included among differential diagnoses for pituitary masses, and for subacute blindness in dogs. Where possible, we advocate biopsy-confirmation of hypophysitis prior to timely intervention with anti-inflammatory treatment.
\end{abstract}

Keywords: Hypophysitis, Central blindness, Insulin-like growth factor-1, Magnetic resonance imaging, Pituitary tumour, Standard Poodle

\section{Background}

Pituitary masses can represent neoplastic, cystic, infectious and/or inflammatory pathology. In dogs, the most common aetiology is neoplastic; macroadenomas, invasive adenomas and adenocarcinomas tend to present in mature animals, whilst the less common suprasellar germ cell tumour presents in younger dogs [1]. Cystic

\footnotetext{
* Correspondence: nina.rzechorzek@ed.ac.uk

${ }^{1}$ Centre for Clinical Brain Sciences, University of Edinburgh, Edinburgh EH16 $4 \mathrm{SB}, \mathrm{UK}$

${ }^{2}$ Royal (Dick) School of Veterinary Studies and Roslin Institute, University of Edinburgh, Easter Bush Campus, Roslin, Midlothian EH25 9RG, UK

Full list of author information is available at the end of the article
}

and inflammatory masses such as Rathke's cleft cysts and immune-mediated lymphocytic hypophysitis occur far less frequently [1]. These lesions are however important to identify, given their potential to have a radically different prognosis relative to neoplasia if managed appropriately [2,3]. Differentiating each of the above aetiologies using advanced imaging is problematic, since they exhibit variable and overlapping radiological features. For example with MRI, all of these masses can appear T2-weighted (T2w) hyperintense to normal grey matter, with variable T1-weighted (T1w) intensity, contrast enhancement, and varying degrees of perilesional oedema; neoplastic lesions can also have secondary cystic or 
haemorrhagic foci [1]. In humans, typical MRI features of hypophysitis include symmetrical pituitary enlargement, loss of normal neurohypophyseal $\mathrm{T} 1 \mathrm{w}$ hyperintensity, and homogeneous contrast enhancement [1], however complete radiological descriptions of canine hypophysitis are lacking $[1,4,5]$.

Clinical signs associated with pituitary neoplasms depend on their size and secretory properties; an important tumour in the dog is the corticotroph adenoma resulting in hypercortisolism [2]. Non-functional pituitary masses become clinically relevant when their mass effect induces pituitary dysfunction (leading to a range of endocrinopathies such as hypothyroidism and central diabetes insipidus) and/or neurological signs including changes in mentation, behaviour, or appetite, abnormal gait, seizures, visual loss and other cranial nerve deficits $[2,6]$. Human hypophysitis is subclassified according to the structures affected (adenohypophysitis, infundibuloneurohypophysitis or pan-hypophysitis), and can be primary (autoimmune), or secondary to systemic disease, local lesions or immunomodulatory drugs [7]. Primary hypophysitis is further categorized histopathologically as lymphocytic, granulomatous or xanthomatous - however the pathogenesis of each remains ill-defined [3]. Lymphocytic and granulomatous hypophysitis typically disrupt adrenal, gonadal and thyroidal axes, and produce diabetes insipidus and visual deficits [3]. Only five cases of canine hypophysitis have been reported (Table 1); none of these presented with visual deficits and all resulted in a grave outcome $[4,5,8-11]$. The aim of this report is to describe the successful treatment of presumptive hypophysitis in a dog, resolving all associated clinical signs including blindness and suspected diabetes insipidus. Further we provide advanced imaging details of the mass lesion before treatment and after apparent macroscopic resolution. Finally we compare and contrast our findings to previously reported cases in this species as well as humans, and discuss factors that may contribute to the development of hypophysitis.

\section{Case presentation}

A 1-year-and-seven-month-old neutered male Standard Poodle presented to a primary veterinarian with PUPD, shivering and mild pyrexia $\left(39.3{ }^{\circ} \mathrm{C}\right)$. Ongoing medication included oclacitinib maleate ${ }^{1}(0.45 \mathrm{mg} / \mathrm{kg}$ orally every $12 \mathrm{~h}$ ) for atopic dermatitis. A urine dipstick test was normal, but after two days without improvement, amoxicillin-clavulanate $^{2}(15.8 \mathrm{mg} / \mathrm{kg}$ orally every $12 \mathrm{~h}$ for 14 days $)$ and meloxicam ${ }^{3}(100 \mu \mathrm{g} / \mathrm{kg}$ orally every $24 \mathrm{~h}$ for 5 days) were prescribed. 6 days later, the dog represented with 4-limb ataxia and blindness. He was subdued and remained polydipsic, with a reduced appetite. Haematology and biochemistry did not yield any clinically significant data, and an adrenocorticotrophic hormone (ACTH) stimulation test was within normal limits. At referral, pale mucous membranes and bradycardia (48 bpm) were noted. Neurological examination revealed visual loss with absent menace responses bilaterally, marked bilateral mydriasis and partially responsive pupillary light reflexes (PLRs). Ophthalmological examination and electroretinography confirmed normal ocular anatomy and normal retinal function respectively. Magnetic resonance imaging (Fig. 1) revealed a T1w isointense, homogeneously contrast-enhancing, symmetrical, dumbbell-shaped pituitary mass of $15 \mathrm{~mm}$ height (pituitary height/brain area $[\mathrm{P} / \mathrm{B}]$ ratio of $0.85[12]$ ), with moderately increased perilesional signal on $\mathrm{T} 2 \mathrm{w}$ images that did not suppress on fluid-attenuated inversion recovery (FLAIR). The lesion was also isointense on $\mathrm{T} 2 *$, and together with the oedema exerted a mass effect on the optic chiasm. Cisternal cerebrospinal fluid (CSF) analysis yielded a lymphocytic pleocytosis (total nucleated cell count 34 per $\mu \mathrm{l}$ with $85 \%$ lymphocytes; protein

Table 1 Reported cases of hypophysitis in the dog

\begin{tabular}{|c|c|c|c|c|c|}
\hline Signalment & Presentation & Treatment & Outcome & Diagnosis & Reference \\
\hline 9 y MN Samoyed & 3 y dermatitis and blepharitis & Medical therapy & Euthanasia & $\begin{array}{l}\text { Lymphoplasmacytic adenohypophysitis } \\
\text { and sebaceous adenitis }\end{array}$ & {$[10]$} \\
\hline $\begin{array}{l}4.5 \text { y FE Great } \\
\text { Pyrenees }\end{array}$ & $\begin{array}{l}2 \mathrm{~m} \text { progressive paresis and } \\
\text { pelvic limb muscle atrophy }\end{array}$ & $\begin{array}{l}\text { Prednisolone } \\
\text { Levothyroxine }\end{array}$ & Euthanasia & $\begin{array}{l}\text { Lymphocytic adenohypophysitis and } \\
\text { adrenalitis with polyendocrine syndrome }\end{array}$ & {$[8]$} \\
\hline $\begin{array}{l}10 \text { y FE } \\
\text { Crossbreed }\end{array}$ & $\begin{array}{l}3 \text { m progressive anorexia and } \\
\text { weight loss; gastroenteritis, } \\
\text { pyrexia }\end{array}$ & $\begin{array}{l}\text { IVFT } \\
\text { Ranitidine } \\
\text { Fenbendazole }\end{array}$ & Sudden death & $\begin{array}{l}\text { Lymphoplasmacytic adenohypophysitis } \\
\text { with adrenal insufficiency and giardiasis }\end{array}$ & {$[11]$} \\
\hline $\begin{array}{l}8 \text { y ME German } \\
\text { Longhaired } \\
\text { Pointer }\end{array}$ & $\begin{array}{l}\text { Acute onset PUPD, exercise } \\
\text { intolerance, dull mentation } \\
\text { and hair coat }\end{array}$ & $\begin{array}{l}\text { Desmopressin } \\
\text { Hypophysectomy } \\
\text { Mannitol }\end{array}$ & Euthanasia & $\begin{array}{l}\text { Lymphocytic hypophysitis with central } \\
\text { diabetes insipidus }\end{array}$ & {$[5]$} \\
\hline $\begin{array}{l}6 \text { y MN } \\
\text { Scottish Terrier }\end{array}$ & $\begin{array}{l}\text { One week progressive lethargy, } \\
\text { anorexia, pelvic limb ataxia }\end{array}$ & Not reported & $\begin{array}{l}\text { Death after acute } \\
\text { severe hypernatraemia }\end{array}$ & $\begin{array}{l}\text { Lymphocytic panhypophysitis with } \\
\text { extension to hypothalamus and } \\
\text { polyendocrine syndrome }\end{array}$ & {$[4]$} \\
\hline
\end{tabular}



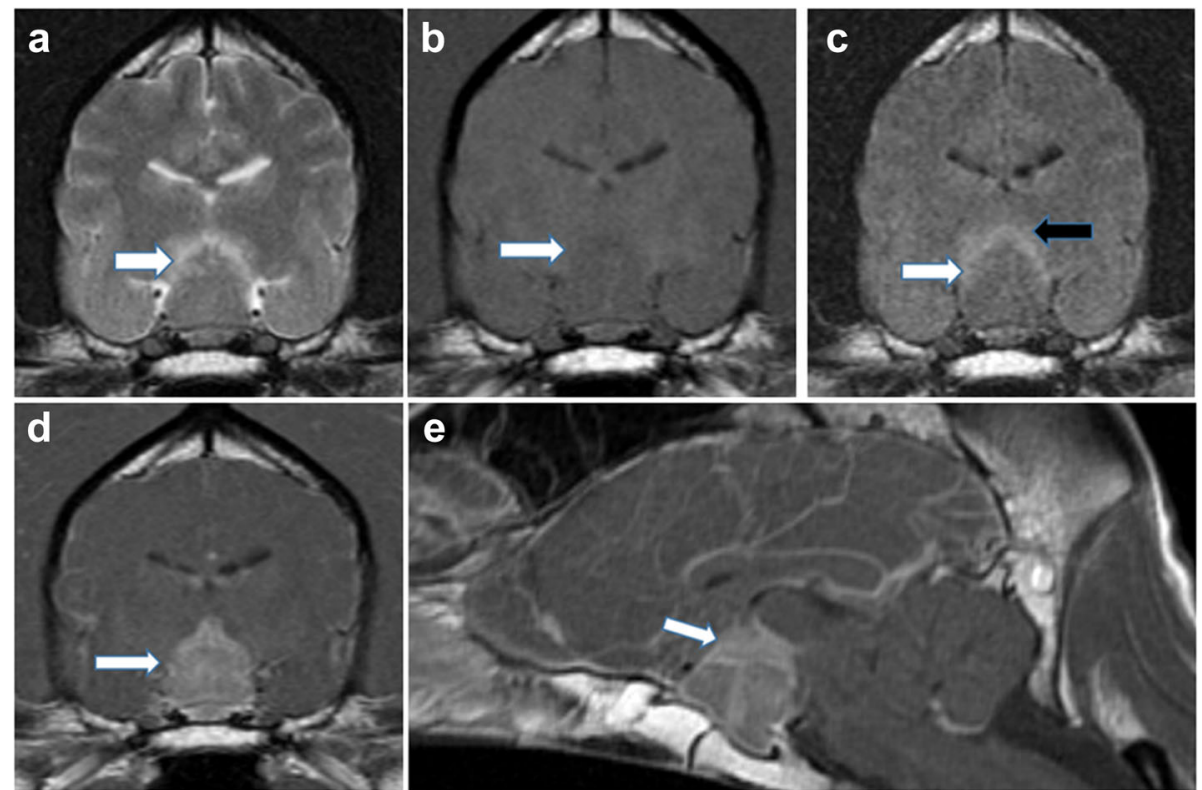

Fig. 1 Transverse T2w, T1w, FLAIR and T1w post-contrast (a, b, c, d) and sagittal T1w post-contrast (e) magnetic resonance images through the pituitary fossa. Note, in all sequences, the enlarged pituitary gland (white arrow) with associated perilesional brain oedema (black arrow) in the FLAIR image (c). Note the avid contrast enhancement of the enlarged pituitary gland on T1w transverse and sagittal post-contrast images (d, e). Images were acquired with a 1.5 T Magneton Essenza MRI scanner

concentration $49 \mathrm{mg} / \mathrm{dL}$ ) which, alongside MRI findings, suggested a neoplastic, immune-mediated or infectious process. The most likely differential in a dog was pituitary neoplasia.

The owner elected for medical management and radiation therapy. Three days after commencing prednisolone $^{4}(0.91 \mathrm{mg} / \mathrm{kg}$ orally every $24 \mathrm{~h})$, PLRs were intact, and the visual function and gait were improving. Polydipsia however persisted, and urinalysis showed an inactive sediment with urine specific gravity (USG) of 1.010. Partial central diabetes insipidus and/or the influence of prednisolone treatment were considered as potential contributing factors. After a further 9 days, the neurological signs had abated; the dog was completely visual but expressed marked PUPD. Vasopressin analogue, desmopressin ${ }^{5}$ was commenced at $10 \mu \mathrm{g} / \mathrm{kg}$ (4 drops in each eye every $12 \mathrm{~h}$ ). The dog was transferred a week later to a second referral hospital for radiation therapy planning. The PUPD had improved, but there was generalized muscle atrophy and weight loss (of $1.8 \mathrm{~kg}$ ), with a body condition score of $3 / 9$. Neurologically the dog was normal. Repeated haematology and biochemistry revealed increased cholesterol (321 $\mathrm{mg} / \mathrm{dL}$; reference range 147-271 $\mathrm{mg} / \mathrm{dL}$ ) and a few reactive lymphocytes. Urinalysis confirmed isosthenuria (USG 1.009). Computed tomography of the head and thorax detected no evidence of metastatic disease and the pituitary gland was normal in size, suggesting resolution of an inflammatory lesion.

Two days later the owner reported further improvement with prednisolone and desmopressin; oclacitinib maleate was being given at maintenance frequency (once daily). Repeated MRI (Fig. 2) indicated complete macroscopic resolution of the mass (pituitary height had reduced from $15 \mathrm{~mm}$ to $4 \mathrm{~mm}$ with a $\mathrm{P} / \mathrm{B}$ ratio of 0.23 ) and was considered to be within normal limits $[1,12])$, with no apparent residual oedema or compression of surrounding tissues. We were not aware of any literature reporting such a dramatic response of a canine pituitary neoplasm to palliative medical treatment alone [2]. On this basis, the differentials included primary hypophysitis, iatrogenically-induced hypophysitis [7], hypophysitis secondary to a ruptured cyst of Rathke's pouch [1,13] or an infection [1, 10], and sellar xanthogranuloma [9]. Serology for Toxoplasma and Neospora was negative, whilst endocrine serology (Table 2) was consistent with hyposomatotropism, which can occur secondarily to hypophysitis [5]. Given the possibility of an immunemediated aetiology, oclacitinib maleate was curtailed and prednisolone was tapered over 10 weeks. Two weeks later the dog had gained weight; after a further 4 weeks his urine was hypersthenuric and the PUPD had resolved. Desmopressin was tapered over 5 weeks. During a 14-month follow-up, there has been no recrudescence 

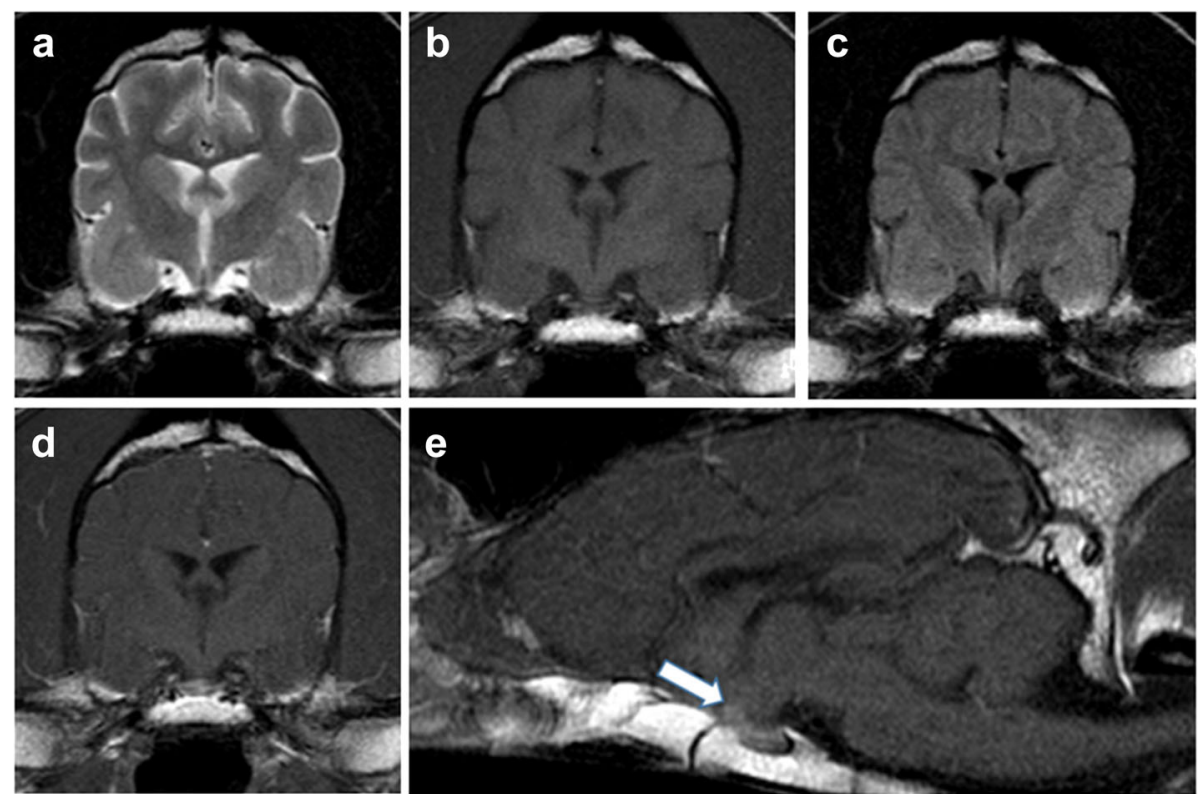

Fig. 2 Transverse T2w, T1w, FLAIR and T1w post-contrast ( $\mathbf{a}, \mathbf{b}, \mathbf{c}, \mathbf{d})$ and sagittal T1w post-contrast (e) magnetic resonance images through the pituitary fossa. Note, in all sequences, the normal appearance of the pituitary gland in the pituitary fossa; pituitary height was $4 \mathrm{~mm}$. Note the contrast enhancement of the normal pituitary gland (white arrow) on T1w sagittal post contrast image (e). Images were acquired with a 1.5 T Philips Burgess Diagnostic MRI scanner

of the clinical signs and the dog has been without treatment for 11 months.

\section{Discussion}

The rapid emergence of subdued behaviour, reduced appetite, and blindness described above resemble common symptoms of hypophysitis in humans including headache and visual disturbances [3]. These signs are also consistent with a histpathologically-confirmed case of lymphocytic panhypophysitis in a Scottish Terrier [4];

Table 2 Endocrinology panel ${ }^{a}$

\begin{tabular}{llll}
\hline Analyte & Value & Unit & Reference range \\
\hline $\begin{array}{l}\text { Thyroxine (T4) by RIA } \\
\text { Free T4 equilibrium }\end{array}$ & 16.6 & $\mathrm{nmol} / \mathrm{l}$ & $13-52$ \\
dialysis (RIA ${ }^{\mathrm{b}}$ ) & 7.1 & $\mathrm{pmol} / \mathrm{l}$ & $7-40$ \\
$\begin{array}{l}\text { TSH by IRMA } \\
\text { Thyroid antiglobulin }\end{array}$ & 0.23 & $\mathrm{ng} / \mathrm{ml}$ & $<0.41$ \\
$\begin{array}{l}\text { antibody } \\
\text { IGF-1 }\end{array}$ & 47 & $\mathrm{ng} / \mathrm{ml}$ & $>200$ \\
& & & breeds adults of large \\
& & & $>500$ puppies \\
& & & $>50$ dwarfism \\
& & & $>1000$ acromegaly
\end{tabular}

a (NationWide Specialist Laboratories, Cambridge; Canine Platinum Thyroid Profile

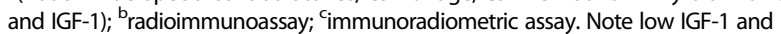
borderline low free T4, with normal total T4, TSH and thyroid antiglobulin antibody. TSH thyroid stimulating hormone, IGF-1 insulin-like growth factor-1 visual dysfunction was not reported in that dog, which could be due to a more dorsal (rather than rostral) extension of the lesion relative to our case [4]. By contrast, canine pituitary neoplasms tend to present more insidiously, and visual dysfunction would likely only be seen as a late-emerging sign in the few cases that had gone untreated, or non-functional tumours that had remained clinically silent for a prolonged period [2]. Occasionally, pituitary apoplexy can present secondary to acute haemorrhage within a neoplastic lesion [14], but the lack of $\mathrm{T} 2$ * signal void in our case makes haemorrhage highly unlikely. Magnetic resonance is the preferred imaging modality for hypophysitis in humans, but has only been described for two dogs, both of which had inflammatory extension to other parts of the brain [1, 4]. The isointensity of the canine mass on T1w images, together with marked contrast enhancement and lack of cystic changes is consistent with a lymphocytic or granulomatous subtype [3]. The shape, hyperintensity on T2w sequences, and lack of $\mathrm{T} 2 *$ signal void are additional features of this lesion which match those described by Oliveira et al. [4]. By contrast both to our report and the human literature, the authors refer to a hypointensity (rather than a loss of normal pituitary hyperintensity) on pre-contrast $\mathrm{T} 1 \mathrm{w}$ images $[1,4]$. As expected due to its rich vascular supply, the normal post-treatment pituitary gland in our Standard Poodle remained markedly contrast-enhancing relative to brain tissue, with a focal $\mathrm{T} 1$ hyperintensity and isointensity to cortical grey matter on $\mathrm{T} 2 \mathrm{w}$ sequences 
(Fig. 2) [1]. Alongside the CSF results, our case is therefore most consistent with a lymphocytic pan-hypophysitis [3, 5, 9] - although confirmation of hypophysitis and its subclassification would require histopathology. In humans, a diagnosis of primary hypophysitis is often based on relevant symptoms together with MRI findings because surgery is not needed for resolution [7]. Since the dog's clinical signs and imaging abnormalities responded so dramatically to medical management, an invasive biopsy could not be justified. Likewise, transsphenoidal hypophysectomy can be complicated for these lesions [5] and the large $\mathrm{P} / \mathrm{B}$ ratio of the mass would have increased the risk of post-operative mortality for hypophysectomy [15]. Although bacterial and canine distemper virus infections were not completely excluded, the authors consider these to be extremely unlikely given the nature and course of clinical signs in this dog.

Adissu et al. [8] likened their hypophysitis case to 'Schmidt's syndrome' - a human condition comprising 2 out of 3 of the major endocrine disorders (hypoadrenocorticism, hypothyroidism and type I diabetes mellitus), and recently described in a Dobermann Pinscher [16]. Polyendocrinopathy was not confirmed in our Standard Poodle, but extended endocrine serology was performed after corticosteroid treatment had commenced, which may have impacted upon endocrine axes, and thus serum levels of the parameters tested. Despite this, the free T4 was borderline low (Table 2) and overall, the thyroid profile was almost identical to that of a Great Pyrenees with lymphocytic adenohypophysitis and confirmed polyendocrinopathy [8]. If treatment had been delayed further in our case, it is possible that hypothyroidism may have emerged as part of the clinical picture, or at least serologically. Our IGF-1 and free T4 results are also consistent with another histopathologically-confirmed example of canine lymphocytic hypophysitis [5]. Although prednisolone may have altered the thyroid profile, it should not affect serum IGF-1 in the dog [17]. Clinically therefore, our case is most similar to the Pointer with lymphocytic hypophysitis, in which hypothyroidism and hyposomatotropism occurred secondarily to hypopituitarism, and diabetes insipidus responded to desmopressin [5]. The delayed resolution of PUPD in our Standard Poodle might have resulted from pituitary stalk damage or prednisolone treatment. Absence of visual deficits in the Pointer could be attributed to a slightly smaller P/B ratio of the pituitary mass (0.75 measured on CT images) [5], which in our case was large enough to compress the optic chiasm and potentially also impinge on the optic tracts. The contrasting outcome between these two cases may reflect a combination of prompt administration of corticosteroid (rather than surgical debulking [5]), and the young age of our dog. Irrespectively, it is important to emphasise that without histopathological confirmation, our diagnosis of hypophysitis remains presumptive.

Treatment for human hypophysitis has included debulking, glucocorticoids, azathioprine, methotrexate and radiation therapy [3]. Corticosteroid is recommended initially for lymphocytic or granulomatous forms where vision is not at risk, but steroid can fail to produce long-term resolution [3]. Pre- or post-surgical glucocorticoid reduced pituitary size in $75 \%$ of patients with the lymphocytic form of hypophysitis, but was less effective in other subtypes [3]. Neoplasia is not excluded by mass size reduction and resolution of visual deficits, which can be achieved medically in patients with aggressive pituitary adenomas [18]. Functional pituitary adenoma was however ruled out in this dog by the combined results of endocrinological testing [5], the extent of radiological change, and the clinical improvement following medical management alone [2]. Radiation therapy is typically recommended for canine pituitary neoplasms, but there is little evidence that it can reverse any visual dysfunction associated with these [2, 6]. For dogs that receive no therapy or only symptomatic treatment (which may include corticosteroid), median survival time for pituitary neoplasia ranges from 6 days to 359 days [2, 19 ], and our patient is clinically normal beyond 400 days. One potential caveat is lymphoma, which can affect the pituitary [20] and can respond dramatically to corticosteroid (started at immunosuppressive doses) [21]. However, radiological features of primary pituitary lymphoma are quite distinct from our observations $[22,23]$ and canine lymphoma would generally be expected to progress within 11 months in the absence of specific treatment [2]. There is currently insufficient data to comment on the anticipated response and survival time when canine central nervous system lymphoma is treated with prednisolone as a single agent [19].

Reported cases of canine hypophysitis have ubiquitously resulted in death or euthanasia $[4,5,8-11]$. This does not necessarily imply a poor prognosis; in the past, histological confirmation could be achieved only at necropsy $[4,8,10,11]$. Although surgical biopsies of pituitary masses have been introduced in veterinary medicine [24], they are rarely performed due to financial and technical limitations - the one reported attempt at hypophysectomy specifically for canine hypophysitis resulted in peri-operative euthanasia [5]. In most of the cases listed in Table 1, anti-inflammatory treatment was not attempted based on the suspicion of a neoplastic process. Prednisolone was administered to one dog, but not until 2 months after the onset of clinical signs [8]. We cannot presume that every hypophysitis case would be steroid-responsive; ideally surgical biopsy should be recommended prior to considering treatment options for pituitary masses. However where biopsy is not 
possible (and/or consent is withheld), it may be prudent to institute corticosteroid as soon as hypophysitis is suspected, especially in otherwise healthy dogs.

Relative to previous cases, our Poodle was remarkably young; we consider therefore that some trigger may have predisposed him to this condition prematurely. Notably, oclacitinib maleate treatment commenced prior to the onset of signs, and twice-daily dosing continued beyond the recommended loading period [25]. We have no evidence that oclacitinib maleate acts as an inciting or permissive factor for this disorder. We would however caution against the use of janus kinase inhibitors where potentially life-threatening immune-mediated conditions are suspected, and where these have developed alongside treatment. Iatrogenically-induced hypophysitis is recognised in human patients treated with ipilimumab [26], sitting within a spectrum of endocrinological side effects of immune checkpoint inhibitors and tyrosine kinase inhibitors $[27,28]$. In most instances, this can be managed with glucocorticoids and hormone replacement therapy [29]. Interestingly, polydipsia, anorexia, lethargy and increased serum cholesterol were reported side effects in early field trials of oclacitinib maleate in the dog [25]. However, features that make iatrogenically-induced hypophysitis less likely in this case include a marked (rather than a moderate) pituitary enlargement, visual loss, and suspected diabetes insipidus [7].

Genetic diversity of the Standard Poodle is unevenly distributed across the dog leukocyte antigen (DLA) class I and II regions, such that the most inbred dogs are more susceptible to complex autoimmune diseases [30]. Among these, sebaceous adenitis and hypoadrenocorticism have presented alongside hypophysitis in other breeds $[8,10]$. One suggested mechanism is that an aberrant immune response targets a unique surface antigen shared by cells of the adenohypophysis and sebaceous glands [10], however this remains untested. Cramer et al. [9] reported sellar xanthogranuloma in a Standard Poodle which also had mild hypercholesterolaemia, a low free T4, and behavioural changes [9]. However, by contrast to the case reported here, the presentation included a year of premonitory PUPD and cystic cavities within the mass [9]. Overall, the combination of atopy, thyroxine dysregulation, hyposomatotropism and hypophysitis in a Standard Poodle raises suspicion of an immune-mediated syndrome linked to the DLA region [30]. This is of interest from a classification perspective, since the co-existence of other autoimmune disorders in humans tends to occur only with the lymphocytic form of hypophysitis [3].

\section{Conclusions}

In conclusion, we describe a presumptive case of hypophysitis in a dog with associated blindness, hyposomatotropism and suspected central diabetes insipidus. All clinical signs and radiological findings resolved after treatment with corticosteroids and the dog remains clinically normal 14 months following diagnosis, and 11 months following discontinuation of all treatments. Features that distinguish this case from previously reported instances of canine hypophysitis include a relatively young age at presentation, and long-term resolution in response to early medical management. Although visual deficits are noted frequently in human hypophysitis and sometimes with other canine pituitary masses $[2,3,6]$, this is the first report of presumptive hypophysitis-induced blindness in the dog. MRI features of hypophysitis have been reported sporadically in canines $[1,4]$ and are similar to those described here. However, these radiological features are not specific for the disorder and cannot exclude other more common canine pituitary mass lesions. For this reason, the authors cautiously favour biopsy-confirmation of hypophysitis followed by anti-inflammatory corticosteroid and/or radiation therapy if available. Where biopsy is contraindicated, or where severe clinical signs demand urgent management, glucocorticoid might be considered. Though rare, hypophysitis should be included as a differential for pituitary lesions in dogs, including those presenting with visual loss.

\section{Endnotes \\ ${ }^{1}$ Apoquel, Zoetis UK Limited, Surrey, UK. \\ ${ }^{2}$ Clavaseptin, Vetoquinol, Buckingham, UK. \\ ${ }^{3}$ Metacam $1.5 \mathrm{mg} / \mathrm{ml}$ oral suspension for dogs, Boehringer Ingelheim Limited, Berkshire, UK. \\ ${ }^{4}$ Prednidale, Dechra Veterinary Products. \\ ${ }^{5}$ DDAVP $100 \mu \mathrm{g} / \mathrm{ml}$ solution.}

\section{Abbreviations}

CSF: Cerebrospinal fluid; CT: Computed tomography; FLAIR: Fluid-attenuated inversion recovery; IGF-1: Insulin-like growth factor-1; MRI: Magnetic resonance imaging; P/B: Pituitary height/brain area; PLR: Pupillary light reflex;

PUPD: Polyuria/polydipsia; T1w: T1-weighted; T2w: T2-weighted; USG: Urine specific gravity

\section{Acknowledgements}

The authors gratefully acknowledge Juan Carlos Serra and Jessica Lawrence of the Oncology Service, Royal (Dick) School of Veterinary Studies, Michael Macfarlane and Jenny Helm of the Oncology Service, Small Animal Hospital, School of Veterinary Medicine, University of Glasgow, and the patient's owner for their support of this work.

\section{Funding}

NMR is funded by a Wellcome Trust Integrated Training Fellowship for Veterinarians (096409/Z/11/Z). Funding sources did not have any involvement in the study design; the collection, analysis and interpretation of data; writing of the report; or the decision to submit the article for publication.

\section{Availability of data and materials}

The data generated and/or used during the work-up of this case are not publicly available in the interests of retaining patient confidentiality.

Authors' contributions

NMR: This author wrote the article and contributed to the clinical assessment, diagnosis, treatment and follow-up of the case. TL: This author contributed to the advanced imaging of the lesion, compiled figure images, and helped to 
write the manuscript. CS: This author contributed to the initial clinical assessment and diagnostic work-up of the case, provided images, and helped to write the manuscript. KMH: This author supervised the clinical assessment, diagnosis, and treatment of the case and helped to write the manuscript. All authors read and approved the final manuscript.

\section{Authors' information}

NMR is a Wellcome Clinical Fellow and post-doctoral researcher currently training in clinical veterinary neurology and neurosurgery under the supervision of $\mathrm{KMH}$, a European and RCVS Recognised Specialist in Veterinary Neurology (DipECVN), an American certified Specialist in Veterinary Internal Medicine (ACVIM(Neurology)), and a Senior Lecturer in Veterinary Neurology. TL is a European Specialist in Veterinary Diagnostic Imaging (DipECVDI) and a Lecturer in Diagnostic Imaging. CS is a European Specialist in Veterinary Neurology (DipECVN) and a Lecturer in Clinical Neurology.

\section{Competing interests}

The authors declare that they have no competing interests.

\section{Consent for publication}

The patient's owner provided written, informed consent for the inclusion of their pet's information in this manuscript for publication.

\section{Ethics approval and consent to participate}

The patient's owner provided written, informed consent for the clinical assessment, diagnostic work-up, treatment and follow-up of their pet.

\section{Author details}

${ }^{1}$ Centre for Clinical Brain Sciences, University of Edinburgh, Edinburgh EH16 4SB, UK. ${ }^{2}$ Royal (Dick) School of Veterinary Studies and Roslin Institute, University of Edinburgh, Easter Bush Campus, Roslin, Midlothian EH25 9RG, UK. ${ }^{3}$ The Neurology Service, Small Animal Hospital, School of Veterinary Medicine University of Glasgow, Garscube Campus, Bearsden Road, Glasgow G61 1QH, UK.

Received: 7 January 2017 Accepted: 21 February 2017

Published online: 28 February 2017

\section{References}

1. Wisner ER, Zwingenberger AL:. Section 2.2.9 Sellar and Parasellar Region. In: Wisner ER, Zwingenberger AL. Atlas of Small Animal CT and MRI. Hoboken: John Wiley \& Sons; 2015. p. 244-263.

2. Withrow SJ, Vail DM, Page RL. Withrow \& MacEwen's Small Animal Clinical Oncology. Fifth Edition. Philadelphia: Saunders, Elsevier Inc; 2013. pp. 189-190 and 504-505.

3. Gutenberg A, Hans V, Puchner MJ, Kreutzer J, Brück W, Caturegli P, et al. Primary hypophysitis: clinical-pathological correlations. Eur J Endocrinol. 2006;155:101-7.

4. Oliveira M, Polledo L, Adamany J, Wessmann A, Graham P, Dhumeaux M, et al. Hypophysitis in a Scottish Terrier with associated panhypopituitarism and hypothalamitis mimicking a pituitary gland neoplasia. Proceedings of the $29^{\text {th }}$ Annual Symposium of the European Society of Veterinary Neurology and European College of Veterinary Neurology. 2016 September 15 to 17, Edinburgh, UK, p. 41-42.

5. Meij BP, Voorhout G, Gerritsen RJ, Grinwis GC, ljzer J. Lymphocytic hypophysitis in a dog with diabetes insipidus. J Comp Pathol. 2012;147:503-7.

6. Davidson MG, Nasisse MP, Breitschwerdt EB, Thrall DE, Page RL, Jamieson VE. Acute blindness associated with intracranial tumors in dogs and cats: eight cases (1984-1989). J Am Vet Med Assoc. 1991;199:755-8.

7. Albarel F, Gaudy C, Castinetti F, Carré T, Morange I, Conte-Devolx B, et al. Long-term follow-up of ipilimumab-induced hypophysitis, a common adverse event of the anti-CTLA-4 antibody in melanoma. Eur J Endocrinol. 2015;172:195-204.

8. Adissu HA, Hamel-Jolette A, Foster RA. Lymphocytic adenohypophysitis and adrenalitis in a dog with adrenal and thyroid atrophy. Vet Pathol. 2010:47:1082-5.

9. Cramer SD, Miller AD, Medici EL, Brunker JD, Ritchey JW. Sellar xanthogranuloma in a dog. J Vet Diagn Invest. 2011;23:387-90.

10. McAllister MM. Adenohypophysitis associated with sebaceous gland atrophy in a dog. Vet Pathol. 1991;28:340-1.
11. Wolfesberger B, Fuchs-Baumgartinger A, Schwendenwein I, Zeugswetter F, Shibly S. Sudden death in a dog with lymphoplasmacytic hypophysitis. J Comp Pathol. 2011;145:231-4.

12. Kooistra H, Voorhout G, Mol J, Rijnberk A. Correlation between impairment of glucocorticoid feedback and the size of the pituitary gland in dogs with pituitary-dependent hyperadrenocorticism. J Endocrinol. 1997;152:387-94.

13. Hama S, Arita K, Tominaga A, Yoshikawa M, Eguchi K, Sumida M, et al. Symptomatic Rathke's cleft cyst coexisting with central diabetes insipidus and hypophysitis: case report. Endocr J. 1999;46:187-92.

14. Beltran E, Dennis R, Foote A, De Risio L, Matiasek L. Imaging diagnosis: pituitary apoplexy in a cat. Vet Radiol Ultrasound. 2012:53:417-9.

15. van Rijn SJ, Galac S, Tryfonidou MA, Hesselink JW, Penning LC, Kooistra HS, Meij BP. The influence of pituitary size on outcome after transsphenoidal hypophysectomy in a large cohort of dogs with pituitary-dependent hypercortisolism. J Vet Intern Med. 2016;30:989-95.

16. Cartwright JA, Stone J, Rick M, Dunning MD. Polyglandular endocrinopathy type II (Schmidt's syndrome) in a Dobermann pinscher. J Small Anim Pract. 2016;57:491-4.

17. Tvarijonaviviute A, Tecles F, Carillo JM, Rubio M, Ceron JJ. Serum insulin-like growth factor-1 in dogs: performance characteristics of an automated assay and study of some sources of variation. Can J Vet Res. 2010;75:312-6.

18. Di leva A, Rotondo F, Syro LV, Cusimano MD, Kovacs K. Aggressive pituitary adenomas - diagnosis and emerging treatments. Nat Rev Endocrinol. 2014;10:423-35.

19. Hu H, Barker A, Harcourt-Brown T, Jeffery N. Systematic review of brain tumour treatment in dogs. J Vet Intern Med. 2015;29:1456-63.

20. Giustina A, Gola M, Doga M, Rosei EA. Clinical Review 136: Primary lymphoma of the pituitary: an emerging clinical entity. J Clin Endocrinol Metab. 2001;86: 4567-75.

21. Squire RA, Bush M, Melby EC, Neeley LM, Yarbrough B. Clinical and pathologic study of canine lymphoma: clinical staging, cell classification, and therapy. J Natl Cancer Inst. 1973;51:565-74.

22. Kaufmann TJ, Lopes MB, Laws Jr ER, Lipper MH. Primary sellar lymphoma: radiologic and pathologic findings in two patients. AJNR Am J Neuroradiol. 2002;23:364-467.

23. Layden BT, Dubner S, Toft DJ, Kopp P, Grimm S, Molitch ME. Primary CNS lymphoma with bilateral symmetric hypothalamic lesions presenting with panhypopituitarism and diabetes insipidus. Pituitary. 2011;14:194-7.

24. Meij BP, Voorhout G, van den Ingh TS, Hazewinkel HA, Teske E, Rijnberg A Results of transsphenoidal hypophysectomy in 52 dogs with pituitarydependent hyperadrenocorticism. Vet Surg. 1998;27:246-61.

25. National Office of Animal Health (NOAH) Compendium of Small Animal Medicines. Enfield, UK. 2015. http://www.noahcompendium.co.uk/. Accessed 24 Jun 2016.

26. Faje A. Immunotherapy and hypophysitis: clinical presentation, treatment, and biologic insights. Pituitary. 2016;19:82-92.

27. Lodish MB, Stratakis CA. Endocrine effects of broad-acting kinase inhibitors. Endocr Relat Cancer. 2010;17:R233-44.

28. Torino F, Corsello SM, Salvatori R. Endocrinological side-effects of immune checkpoint inhibitors. Curr Opin Oncol. 2016;28:278-87.

29. Araujo PB, Coelho MC, Arruda M, Gadelha MR, Neto LV. Ipilimumab-induced hypophysitis: review of the literature. J Endocrinol Invest. 2015;38:1159-66.

30. Pedersen NC, Brucker L, Tessier NG, Liu H, Penedo MC, Hughes S. The effect of genetic bottlenecks and inbreeding on the incidence of two major autoimmune diseases in standard poodles, sebaceous adenitis and Addison's disease. Canine Genet Epidemiol. 2015;2:14

\section{Submit your next manuscript to BioMed Central and we will help you at every step:}

- We accept pre-submission inquiries

- Our selector tool helps you to find the most relevant journal

- We provide round the clock customer support

- Convenient online submission

- Thorough peer review

- Inclusion in PubMed and all major indexing services

- Maximum visibility for your research

Submit your manuscript at www.biomedcentral.com/submit 